\title{
POTENCIAL BIOTECNOLÓGICO DE MICRORGANISMOS DO SOLO NA OLIVICULTURA DO BRASIL: UMA REVISÃO
}

\author{
Samara Maria Lopes Costa* \\ Rogério Melloni** \\ Gustavo Magno dos Reis Ferreira***
}

RESUMO: A olivicultura foi introduzida no Brasil por volta do século XIX, em algumas regiões com condições ambientais propícias, como Sul e Sudeste. Porém, o cultivo não prosperou por falta de estudos relacionados às exigências de solo, clima e outros fatores que afetam diretamente a produtividade desta cultura. Assim, pela baixa produção comercial, o país necessita importar todo azeite de oliva e azeitona de países tradicionalmente produtores. O objetivo deste estudo foi realizar uma revisão bibliográfica sobre os trabalhos que abordam desenvolvimento e produção de oliveiras, com enfoque no Brasil, enfatizando aqueles que envolvem aspectos relacionados às interações com microrganismos, como fungos micorrízicos arbusculares (FMAs) e rizobactérias, grupos esses de reconhecido efeito no crescimento e desenvolvimento de plantas. Verificou-se que vários estudos têm sido realizados no exterior abordando FMAs e rizobactérias em oliveiras, com resultados expressivos no que se referem ao crescimento e desenvolvimento de plantas coinoculadas, além de melhorias de resistência a metais pesados e fitopatógenos, tanto em condições de viveiro quanto em campo. No entanto, no Brasil, apesar de grande potencial de cultivo de oliveira, principalmente em função de sua extensão territorial e riqueza climática e biológica, poucos estudos têm sido conduzidos abordando essas relações microbiológicas, o que podem dificultar o entendimento e o crescimento da olivicultura no país.

PALAVRAS-CHAVE: Fungos micorrízicos; Inoculação; Olea europaea; Rizobactérias.

\footnotetext{
Mestre em Meio Ambiente e Recursos Hídricos, pela Universidade Federal de Itajubá (Unifei), Itajubá (MG), Brasil.

** Doutor em Agronomia e docente titular do Instituto de Recursos Naturais, da Universidade Federal de Itajubá (Unifei), Itajubá (MG), Brasil. E-mail: rogerio.melloni@gmail.com

**** Doutor em Microbiologia Agrícola, pela Universidade Federal de Lavras (Ufla), Lavras (MG), Brasil.
} 


\title{
BIOTECHNOLOGICAL POTENTIAL OF SOIL MICROORGANISMS IN OLIVE TREES IN BRAZIL: A REVIEW
}

\begin{abstract}
Olive crop was introduced in several regions of Brazil in the 19th century, especially in the southern and southeastern regions. Crops were a failure due to lack of studies on soil, climate and other factors that directly affected productivity. Due to low commercial production, Brazil imports all olive oil and olives from producing countries. A bibliographical review has been developed on publications on the development and production of olives, with special reference to Brazil, highlighting those which involve aspects related to the interactions with microorganisms, such as arbuscular mycorrhizal fungi (AMFs) and rhizo-bacteria. They are groups that affect the growth and development of the plants. Several studies have been undertaken abroad on AMFs and rhizo-bacteria in olive trees with significant results on growth and development of co-inoculated plants, improvement in resistance to heavy metals and phytopathogens in the greenhouse and in the field. In spite of the great capacity for the development of olive crops, especially due to the country's extension and climatic and biological richness, few studies have been undertaken on microbiological relationships, and thus retard data on and for the growth of olive crops.
\end{abstract}

KEY WORDS: Mycorrhizal fungi; Inoculation; Olea europaea; Rizobacteria.

\section{INTRODUÇÃO}

A oliveira (Olea europaea L.) é uma planta de porte arbóreo que pertence à família botânica Oleaceae, produz frutos comestíveis e apresenta um ciclo de vida perene, destacando-se por sua longevidade (COUTINHO et al., 2015). Seus frutos são consumidos mundialmente tanto na forma de azeitona de mesa quanto para a extração do azeite (WREGE et al., 2009).

A origem da espécie compreende uma região extensa do Mediterrâneo, que vai desde o Sul do Cáucaso até o Egito (COUTINHO et al., 2015). Por conta de ser uma planta de clima temperado e apresentar estrutura xerofítica, ou seja, com adaptações para viver em ambientes de clima seco, se desenvolve satisfatoriamente até mesmo em ambientes com pequenos índices pluviométricos e verões extensos (WREGE et al., 2009). 
Diferentes fatores climáticos influenciam no crescimento e desenvolvimento dessa espécie, como temperatura, clima, umidade relativa e pluviometria. Neste contexto, após o desenvolvimento de diversos trabalhos com plantio de oliveiras em países do Mediterrâneo, verificou-se que a temperatura adequada para a ocorrência de frutificação efetiva, chamada de fruit set, deve ser de $25^{\circ} \mathrm{C}$ a 35 ${ }^{\circ} \mathrm{C}$. Porém, as oliveiras têm capacidade de suportar temperaturas próximas 40 ${ }^{\circ} \mathrm{C}$, sem que ocorram queimaduras nos ramos e folhas (ALBA; FLORES; WREGE, 2013). Temperaturas a partir de $10^{\circ} \mathrm{C}$ dão início à floração e, entre $15^{\circ} \mathrm{C}$ e $20^{\circ} \mathrm{C}$, ocorre a plena floração da espécie (NAVARRO; PARRA, 2008). No Brasil, segundo esses mesmos autores, devido à baixa disponibilidade de informações tecnológicas sobre a cultura da oliveira, são necessários mais estudos da ecofisiologia da espécie para verificar se realmente existe relação entre a acumulação de horas-frio e as diferentes fases do ciclo produtivo. No entanto, temperaturas inferiores a $12{ }^{\circ} \mathrm{C}$ podem comprometer e impedir o seu crescimento (TAPIA et al., 2003). Trabalhos relacionados ao melhoramento de cultivares de oliveira, atrelados a técnicas de manejo e, principalmente, à atividade fotossintética, como radiação e temperatura, podem maximizar o seu desenvolvimento (LIVRAMENTO; OLIVEIRA, 2006).

Com relação à pluviometria, a espécie necessita de distribuição regular de chuvas, em média, de 650-800 mm por ano (COUTINHO, 2007). A umidade relativa na fase de frutificação deve ficar entre 60 a $80 \%$, caso contrário há o comprometimento da viabilidade do estigma (WREGE et al., 2009). Portanto, o conhecimento técnico sobre as características da oliveira e as melhores condições climáticas para produção são indispensáveis para o sucesso de seu cultivo.

Além disso, a escolha e o preparo do solo para plantio, aliada aos aspectos físicos e de fertilidade em solos brasileiros, devem ser relevantemente considerados quando do plantio de olivais. Para esses solos, Vieira Neto et al. (2008) recomendam locais de plantios com até $50 \%$ de declividade, de maior exposição à luz solar, boa drenagem, solos profundos com $\mathrm{pH}$ entre 5,5 e 6,5, calagem conforme a necessidade do solo e uso de fertilizantes fosfatados.

Além do conhecimento técnico sobre as características da oliveira e as condições climáticas propícias para sua produção, deve-se levar em conta as especificidades do solo. Estas incluem o conhecimento das relações simbióticas 
que ocorrem no solo, uma vez que são imprescindíveis para o desenvolvimento de plantas, como a simbiose micorrízica, a qual possibilita melhoria do crescimento vegetal de plantas e aumento na tolerância ou resistência contra agentes ambientais adversos (FOLLI-PEREIRA et al., 2012). Outro tipo de interação que ocorre no solo, também de grande importância para as plantas, são as que envolvem as rizobactérias, cuja característica marcante é a produção de hormônios importantes para o desenvolvimento vegetal, como auxina e ácido indolacético (VAFADAR; AMOOAGHAIE; OTROSHY, 2013). Sendo assim, o objetivo desse estudo foi realizar uma revisão bibliográfica, abordando trabalhos de artigos científicos, notas técnicas, capítulos de livros e informações de sites, dos anos de 2003 a 2017, sobre o desenvolvimento e produção de oliveiras, com enfoque no Brasil, principalmente aqueles que envolvem aspectos relacionados às interações com microrganismos.

\section{PRODUÇÃO E CONSUMO NO BRASIL}

O plantio da oliveira, denominada olivicultura, tem sido realizado em todos os continentes, em regiões de clima subtropical ou temperado, como os países do Mediterrâneo, como Itália, Grécia e Tunísia (COUTINHO; RIBEIRO; CAPPELLARO, 2009), ou em países de clima subtropical, como Argentina, Austrália e Chile (TOFOLI et al., 2013). No Brasil, tal cultura se estabeleceu no início do século XIX, em quase todos os estar Estados, porém, com maior expressividade nas regiões Sudeste e Sul, devido às características climáticas serem mais favoráveis para a diferenciação da gema florística e consequentemente para a produção dos frutos (VIEIRA NETO et al., 2008).

Atualmente, o Brasil está entre os 10 países que mais consumem azeite do mundo, o que o torna um grande importador deste óleo vegetal (INTERNATIONAL OLIVE OIL COUNCIL, 2016). A elevação do consumo desses produtos é justificada pela divulgação dos benefícios da dieta mediterrânea na saúde humana, pela entrada de produtos no mercado interno com preços mais acessíveis e aumento do poder aquisitivo de algumas classes sociais.

A importação desses produtos oriundos da oliveira se deve ao fato de a 
produção nacional de azeitona não dispor de um volume suficiente para atender a população, em função de menor expressividade e tecnologia para competir com os concorrentes internacionais (SILVA; MELLO, 2014), além de falta de direcionamento de pesquisas por agências de fomento. Para que a exploração racional da oliveira continue a progredir são necessários mais investimentos em pesquisas. $\mathrm{O}$ insucesso do desenvolvimento da cultura no Brasil se deu até o presente momento por falta de tecnologias e estudos apropriados sobre a espécie, como estudos de zoneamento edafoclimático, levando-se em conta as particularidades de cada cultivar, o conhecimento adequado sobre a fisiologia da floração e frutificação da espécie, a manipulação de tecnologias de produção de azeite, capacitação de técnicos para realização de análises laboratoriais físico-químicas e sensoriais da azeitona de mesa e azeite, do manejo adequado do solo e da planta (ALBA; FLORES; WREGE, 2013).

Para diminuir esse quadro de total dependência de importações, diversos estudos têm sido realizados desde 1940 e tiveram impulso a partir do ano 2000, tais como os de zoneamentos agroclimáticos, edafoclimáticos e econômicos realizados por instituições ligadas ao Ministério da Agricultura. Os resultados envolvem a indicação de regiões brasileiras com as melhores características, aptidões climáticas e edáficas satisfatórias para o desenvolvimento de lavouras em larga escala (MELLO; PINHEIRO, 2012). Atualmente, existem áreas de olivais plantadas em alguns Estados como Rio Grande do Sul, Minas Gerais, Rio de Janeiro e São Paulo (WREGE et al., 2015).

Até o ano de 2012, nas regiões altas da Serra da Mantiqueira, existiam aproximadamente 330 mil plantas de oliveira espalhadas entre 60 produtores e 55 municípios (SILVA et al., 2012). Porém, para atender completamente o mercado interno, com base no volume de azeitonas que são importadas anualmente, é necessário um plantio de 11 milhões de plantas, aproximadamente 62 mil hectares de oliveiras, o que requer bastante pesquisa sobre informações técnicas para sua produção (OLIVEIRA et al., 2012; SILVA et al., 2012).

Em face disso, a Empresa de Pesquisa Agropecuária de Minas Gerais EPAMIG, em Maria da Fé (MG), vem desenvolvendo pesquisas com a oliveira na Fazenda Experimental de Maria da Fé (FEMF), Sul de Minas Gerais, com o intuito de diminuir o volume de importações, obtendo resultados promissores e possibilitando 
a inserção de novas alternativas agrícolas para agricultura familiar, agregando valor ao produto (OLIVEIRA et al., 2009). Além dessas vantagens, por ser uma planta arbórea e de grande longevidade, a oliveira propicia a conservação de solos e mananciais d'água, o que possibilita que regióes de uso agrícola sejam preservadas, evitando o uso intenso do solo e admitindo a integração com outras atividades agrícolas, como a pastagem ou o plantio consorciado com culturas de ciclo anual e de baixo porte (MESQUITA; OLIVEIRA; MESQUITA, 2006).

No entanto, como resultados de alguns estudos, em Minas Gerais, algumas cultivares já demonstraram potencial produtivo e comercial, como as variedades Grapollo, que se destinam à extração de azeite, e a Ascolano, apropriada para a produção de azeitonas de mesa (MELLO; PINHEIRO, 2012). O estudo desenvolvido por Ballus et al. (2014), para determinar o teor de algumas substâncias químicas presentes no azeite de oliva virgem brasileiro de 17 variedades de azeitonas cultivadas na região Sudeste do Brasil, mostrou a viabilidade de alguns azeites para o mercado, porém ainda mais estudos de avaliações sensoriais do azeite são necessários. Já a cultivar Arbequina, de origem espanhola, é a mais cultivada e comercializada no mundo, devido às suas características de fácil adaptação aos sistemas de cultivo e começou a ser cultivada recentemente no Brasil (BORGES et al., 2017).

Como as áreas tradicionais de cultivo em grandes quantidades desta cultura estão ficando esgotadas, nos países onde o cultivo é comum, como Espanha e países mediterrâneos da Europa, novas oportunidades estão sendo abertas aos países sulamericanos (MESQUITA; OLVEIRA; MESQUITA, 2006). Desse modo, a tendência da olivicultura no Brasil é ampliar suas áreas cultivadas, com melhoramento das técnicas de cultivo visando maior produtividade.

\section{QUALIDADE NA PRODUÇÃO DE MUDAS DE OLIVEIRA}

Produzir mudas de qualidade é essencial para a implantação de pomares da cultura da oliveira, de maneira que estes atinjam rendimentos satisfatórios e que atendam as demandas comerciais. Para formação de tais mudas, a estaquia é o método de propagação mais utilizado no Brasil e nos países europeus, na qual 
esta técnica vem sendo melhorada a cada ano, particularmente para o enraizamento de estacas semilenhosas, mediante nebulização intermitente (CABALLERO; DEL RIO, 2006). Na produção de mudas pelo método de propagação vegetativa, a planta apresenta um sistema radicular fasciculado, exibindo três fases distintas na multiplicação: o enraizamento, em que ocorre a emissão de raízes adventícias na base das estacas; a aclimatação, onde ocorre o funcionamento do sistema radicular obtido na fase de enraizamento, e a fase de formação de mudas, em que se obtêm plantas para comercialização, formados com um só caule ou tronco já em saquinhos (COUTINHO et al., 2009).

Para o processo de enraizamento das estacas, utilizam-se estacas medindo de 12 a $15 \mathrm{~cm}$ de comprimento aproximadamente, com um número variado de entrenós, e cada estaca apresenta de dois a três pares de folhas em sua parte apical, sendo que para o enraizamento é indispensável um tratamento hormonal antes de se realizar o plantio das estacas (CABALLERO; DEL RIO, 2006).

O tipo de tratamento hormonal mais utilizado para o enraizamento de estacas consiste em imergir a base das estacas, por cinco segundos, em uma solução de ácido indolbutírico (AIB) diluída em álcool etílico e água 50\%, na concentração de 3 a $4 \mathrm{gL}^{-1}$ (OLIVEIRA et al., 2008). De acordo com o trabalho de Silva et al. (2012), diferentes fatores interferem no processo de enraizamento de estacas de oliveira, dentre eles o período do ano em que se coleta as estacas e a eficiência genética das cultivares. Tais autores observaram que o enraizamento das estacas diferiu entre as cultivares, sendo que o mês de abril propiciou melhor enraizamento para algumas cultivares estudadas (MGS MANZ215 e MGS TAF390), com uma taxa média de enraizamento de $73 \%$.

O êxito do desenvolvimento comercial dessa cultura no Brasil depende da aptidão ao local de plantio, o uso de mudas sadias e a utilização de diferentes cultivares de oliveiras intercaladas ou com auxílio de polinizadores (OLIVEIRA; ANTUNES; SCHUCH, 2006). Além disso, é imprescindível o auxílio de políticas públicas, com incentivos governamentais ao desenvolvimento de olivais em solos brasileiros, para que, assim, estes possam atender a demanda comercial nacional.

Nesse sentido, estudos sobre qualidade do solo para obtenção de mudas saudáveis são fundamentais, levando-se em conta os fatores que possam interferir 
no crescimento e produtividade de oliveiras, como o tipo de solo, seus aspectos físicos e químicos, e, principalmente, os de ordem biológica, como as relações com os microrganismos.

\section{RELAÇÃO DOS MICRORGANISMOS COM AS OLIVEIRAS}

O uso de tecnologias microbiológicas na produção de mudas de oliveiras, em especial envolvendo microrganismos, como os fungos micorrízicos arbusculares (FMAs) e rizobactérias, pode ser uma alternativa e ferramenta de gestão ambiental frente ao uso de insumos agrícolas artificiais (FERREIRA et al., 2015; SILVA et al., 2017). Nesse contexto, a inoculação pode ser utilizada desde a fase de enraizamento de estacas, até o crescimento das mudas e transplantio para o campo. Tais possibilidades de práticas de manejo poderiam contribuir com a oferta de novas tecnologias visando expansão da olivicultura pelo país, em zonas favoráveis, incentivando a agricultura familiar, oferta do produto no mercado interno e redução de gastos com importação.

\subsection{FUNGOS MICORRÍZICOS ARBUSCULARES}

Em princípio, o solo comporta pequena disponibilidade de nutrientes, na qual é compensado pela presença de zonas que apresentam uma elevada atividade biológica (MOREIRA; SIQUEIRA, 2006). Algumas dessas zonas, chamadas de "hot spots", contêm matéria orgânica armazenada e porções do solo próximas às raízes das plantas, chamada de rizosfera, que por sua vez recebe influência dos exsudatos liberados pelas raízes dessas plantas e dos microrganismos (CARDOSO; ANDREOTE, 2016).

Os microrganismos rizosféricos são sensíveis a alterações ambientais e desempenham papel importante nos ciclos biogeoquímicos de nutrientes (ANDREOTE; GUMIERE; DURRER, 2014). Os FMAs fazem parte dessa ampla gama de microrganismos. Esses fungos desempenham papéis essenciais na natureza, apresentando estruturas denominadas hifas, que atuam como uma extensão do 
sistema radicular das plantas e são de extrema importância para absorção efetiva de nutrientes, principalmente o fósforo e água, além de atuaram na estruturação do solo, na tolerância a estresses bióticos e abióticos e resistência a doenças em plantas (CARDOSO; ANDREOTE, 2016).

$\mathrm{Na}$ cultura da oliveira existem diversos trabalhos com relação à associação micorrízica em vários locais do mundo, como na Europa, África e Oriente Médio (ESTAÚN et al., 2003; CHLIYEH et al., 2010; SEIFI et al., 2014). Estaún et al. (2003), na Espanha, estudaram os efeitos da inoculação com FMAs Glomus intraradices e Glomus mosseae no desenvolvimento precoce das plantas, no estabelecimento do campo e no rendimento de colheita da cultivar de oliveira Arbequina, em condições de viveiro e de campo. Como resultados, tanto em viveiro como em campo, os autores concluíram que a inoculação de FMAs foi eficiente na promoção do desenvolvimento precoce das plantas, principalmente por causa da pré-inoculação antes do transplantio para o campo, melhorando o crescimento e produtividade da cultivar Arbequina. Nessa mesma linha, Calvente et al. (2004) desenvolveram um trabalho para analisar a diversidade natural de FMAs na rizosfera de oliveiras maduras da cultivar Arbequina e Leccino cultivadas em campo e determinar a eficiência desses FMAs isolados de oliveiras como inoculantes para as cultivares préestabelecidas. Concluíram que havia, ainda, uma grande necessidade de explorar a diversidade de FMAs para auxiliar na produção de inoculantes a serem aplicados na produção de variedades vegetais, como as cultivares de oliveira.

Já Castillo et al. (2006) avaliaram a capacidade de FMAs proteger a oliveira contra fitopatógenos. Tais autores determinaram o efeito protetor de FMAs sobre o plantio de oliveiras inoculadas com Meloidogyne spp. e determinar se a severidade da irritação da raiz causada por Meloidogyne spp, bem como se reprodução de nematóides em azeitonas, poderia ser reduzida por colonização de FMAs, concluindo que, além da inoculação com FMAs aumentar a proteção contra a referida doença melhorou o crescimento das plantas. Já Porras-Soriano et al. (2009), também na Espanha, confirmaram maior crescimento das plantas sob estresse salino em função de melhoria na absorção de macronutrientes quando as mesmas foram inoculadas com FMAs.

Os trabalhos de Meddad-Hamza et al. (2010), na África, confirmaram maior 
crescimento e resistência ao estresse hídrico quando duas espécies de FMAs foram inoculadas em plantas de oliveira micropropagadas. Já Seifi et al. (2014), no Irã, investigaram a capacidade de duas espécies de FMAs influenciarem em características como crescimento e composição fitoquímicas em cultivares de oliveira (Koroneiki; Valanolia), concluindo, após 80 semanas de plantio, que as duas espécies de FMAs estudadas aumentaram os atributos de crescimento vegetal e composições fitoquímicas, exceto a área foliar. Chliyeh et al. (2010), na África, obtiveram resultados favoráveis no desenvolvimento de cultivares de oliveira Haouzia e Dabbia, após inoculação de uma mistura de FMAs, principalmente na fase de viveiro, tornando as mudas mais resistentes a estresses bióticos e abióticos no campo.

Os estudos de Khabou et al. (2014), também na África, avaliaram o efeito da colonização do FMA Glomus intraradices na raiz de uma cultivar de oliveira Chemlali cultivada sobre substrato contendo várias proporções de gesso. Tais autores concluíram que a interação micorrízica atenuou o efeito depressivo do gesso na cultivar, uma vez que as raízes da cultivar acumularam sulfatos iônicos. Enquanto Calvo-Calvo-Polanco et al. (2016), na Espanha, estudaram o efeito de diferentes FMAs oriundos de diferentes solos sobre crescimento de oliveira, cultivar Picual e suas respostas ao estresse hídrico, concluindo que os FMAs originários de um clima úmido promoveram melhor desempenho em todas as condições quando comparadas com os FMAs provenientes de climas mais áridos.

Ainda na Espanha, os trabalhos de Montes-Borrego, Metsis e Landa (2014) examinaram a estrutura e a diversidade de FMAs na rizosfera de azeitonas cultivadas e silvestres na comunidade de Andaluzia. Os autores utilizaram duas abordagens moleculares independentes da cultura, concluindo que os FMAs exercem grande especificidade com as oliveiras, o que pode facilitar o processo de produção de mudas micorrizadas em viveiro. Já no Norte da Argélia, África, Mekahlia, Beddiar e Chenchouni (2013) avaliaram a porcentagem de colonização radicular por FMAs em oliveiras ao longo de um gradiente climático (sub-úmido, semi-árido e árido), verificando que as raízes de oliveira eram colonizadas por FMAs nos três tipos de clima e independente da estação ou dos anos de estudo (2010-2012).

O mesmo se deu nos trabalhos de Sidhoum e Fortas (2013), também na Argélia, que após inocularem FMAs em estacas herbáceas da oliveira cultivar "Sigoise" 
em condições controladas, verificaram uma melhora significativa no crescimento das plantas. Enquanto Meddad-Hamza et al. (2017), na Argélia, desenvolveram um trabalho para esclarecer como os aspectos climáticos, desde climas desérticos até úmidos, afetam o desenvolvimento de determinados FMAs. Esses autores verificaram que os climas úmidos e subúmidos favorecem a micorrização de mudas de oliveiras, o que, de fato, possibilita a expansão dessa cultura para países que apresentam esse clima, como o Brasil.

Na Tunísia, Mechri et al. (2015) verificaram que a micorrização de mudas de oliveira proporcionou aumento no teor de flavonóides e compostos fenólicos totais nas raízes micorrizadas de oliveira. Esse aumento poderia estar envolvido nos efeitos benéficos da colonização micorrízica sobre o desempenho das oliveiras cultivadas perante as condições mediterrânicas semi-áridas. Resultados semelhantes foram encontrados por Tekaya et al. (2016), também na Tunísia, avaliando o efeito do fungo Rhizophagus irregularis sobre a fotossíntese, pigmentação e absorção de nutrientes de oliveira. Os autores verificaram que plantas micorrizadas, quando comparadas às não micorrizadas, apresentaram várias alterações em parâmetros fisiológicos, como os relacionados à taxa de fotossíntese, absorção de nutrientes e níveis de carboidratos nas folhas e nas raízes, que influenciaram diretamente no desempenho da oliveira.

Da mesma forma, na Argentina, os trabalhos de Bompadre et al. (2013) mostraram que o FMA Rhizophagus irregularis se mostrou eficiente no desenvolvimento das mudas de oliveira na fase de viveiro, facilitando o transplantio para o campo. Melhorias significativas foram observadas na composição de polifenóis nas folhas de oliveira, da cultivar Arbequina com a inoculação de FMAs em trabalhos de Malik, Nuñez e McKeever (2017), nos Estados Unidos, o que possibilitou uma melhoria na qualidade das folhas utilizadas em tratamentos fitoterápicos. Trabalhos de Bati, Santilli e Lombardo (2015), na Itália, comprovaram que, além dos FMAs aumentarem o crescimento e melhorarem a absorção de P em plântulas de oliveira, comportamento já conhecido para outras culturas, tais fungos possibilitaram um aumento da proteção contra manganês $(\mathrm{Mn})$, um metal pesado que quando em excesso se torna tóxico às plantas.

Como observado, em diversos países europeus, da África e do Oriente 
Médio, já existem diversos estudos demonstrando a viabilidade da utilização de FMAs no desenvolvimento de mudas de oliveira. Porém, no Brasil, tais estudos ainda são incipientes, o que justifica o foco do presente trabalho. Os poucos trabalhos presentes são de Vieira, Melloni e Vieira Neto (2011), que constataram a associação micorrízica em diferentes cultivares de oliveira, e de Ferreira et al. (2015), que evidenciaram o efeito desses fungos no crescimento e desenvolvimento de mudas.

\subsection{RIZOBACTÉRIAS}

Bactérias rizosféricas ou rizobactérias, assim como os FMAs e outros grupos de microrganismos, fazem parte da rizosfera. As rizobactérias podem proporcionar maior desenvolvimento às plantas por meio de diferentes mecanismos, como suplementação de nutrientes não disponíveis ou em baixa disponibilidade no solo e pela inibição do desenvolvimento de pragas e patógenos de plantas, com a produção de antibactericidas e antifúngicos (CARDOSO; ANDREOTE, 2016). Sabese, ainda, que essas rizobactérias são responsáveis pela produção de reguladores de crescimento vegetal como auxinas, citocininas, giberelinas, etileno e ácido abscísico (SILVA et al., 2016; VEJAN et al., 2016).

Segundo Vafadar et al. (2013) as rizobactérias promovem o desenvolvimento de plantas graças à produção de hormônios, como as giberelinas e ácido indolacético (AIA), essenciais à planta, mobilização de fosfato, inibição na planta da síntese de etileno, indução nas plantas à resistência sistêmica contra patógenos, produção de sideróforos e antibióticos. Carvalho et al. (2009) demonstraram como o uso de metabólitos produzidos por rizobactérias podem auxiliar no crescimento de plantas. Tais autores constataram que três tipos de rizobactérias produziram substâncias capazes de estimular o crescimento das primeiras folhas do embrião de plantas de trigo, o que as tornaram viáveis ou com potencial de serem exploradas em outras plantas.

O aumento da produtividade de culturas está diretamente relacionado à produção de hormônios pelas rizobactérias, como já citado, pelo fato da produção da auxina permitir o crescimento das raízes e o aumento de pelos radiculares, proporcionando maior absorção de água e nutrientes do solo e, consequentemente, 
o crescimento vegetal (CABALLERO-MELLADO, 2006). Esses hormônios vêm sendo usados para proporcionar maior formação de raízes em espécies ornamentais, florestais, medicinais e em frutíferas (VALMORBIDA et al., 2008).

Neves et al. (2006) ressaltaram que a produção comercial de mudas por estaquia depende da eficiência de enraizamento de cada espécie, da condição do sistema radicular que este foi formado e do crescimento da planta. Além disso, Oliveira et al. (2009) ressaltaram que a temperatura, incidência de luminosidade, a umidade, o tipo de substrato, a lesão na base da estaca e o tipo e a época de coleta são fatores que influenciam no processo de enraizamento.

Com relação à cultura da oliveira, já existem estudos abordando o uso de rizobactérias como promotoras de enraizamento. No Brasil, o trabalho de Silva et al. (2017) demonstrou que alguns isolados de bactérias apresentaram potencial de enraizamento, com comportamento similar ao proporcionado pelo uso do hormônio sintético ácido indolbutírico (AIB). O mesmo ocorreu com os trabalhos de Mariosa (2014), em que alguns isolados de rizobactérias permitiram um maior enraizamento de estacas de oliveira.

Internacionalmente, os trabalhos de Montero-Calasanz et al. (2013), na Espanha, demonstraram o potencial de alguns isolados de rizobactérias produtoras de auxinas na indução do enraizamento de estacas semilenhosas de algumas cultivares de oliveira, em um sistema de agricultura orgânica. Tais autores constataram que, em condições de viveiro, todas as estirpes de rizobactérias testadas foram eficientes no processo de enraizamento de estacas das cultivares de oliveira, quando comparadas ao controle tratado com AIB, o que mostrou a viabilidade do uso dessas bactérias em um sistema de agricultura orgânica.

Schilirò et al. (2012), na Espanha, comprovaram que a rizobactéria Pseudomonas fluorescens PICF7 agiu no biocontrole efetivo em raízes de oliveira contra a doença conhecida como verticilose, desencadeando uma proteção maior nessas raízes, ativando e modulando um conjunto de vias de defesa.

No Egito, os trabalhos de El Taweel, Omar e Shaheen (2014) também evidenciaram resultados benéficos da inoculação de duas rizobactérias sobre 0 crescimento vegetativo, o rendimento, a qualidade do fruto e os teores minerais foliares de Olea europaea 'Manzanillo'. Já Peyvandi et al. (2010), no Irã, estudaram 
a formação e arquitetura radicular de oliveiras inoculadas com Pseudomonas fluorescens, observando uma melhora considerável no comprimento e no número de raízes adventícias e laterais quando comparados ao controle, apenas com AIB.

Como visto, o uso de rizobactérias em cultivares de oliveira é retratado em alguns trabalhos, porém ainda são incipientes. Tal fato justifica o foco do presente trabalho, na tentativa de estudar o papel de alguns isolados de rizobactérias no enraizamento de estacas e no crescimento de mudas de oliveira, nas condições climáticas do Brasil.

\subsection{INTERAÇÃO SIMBIÓTICA DE FMAS E RIZOBACTÉRIAS EM CULTURAS DIVERSAS}

Entender as associações estabelecidas no meio edáfico, principalmente entre os diversos tipos de microrganismos e as plantas, é de grande importância para a ciência. A utilização controlada desses microrganismos presentes na microbiota natural do solo pode reduzir o uso de fertilizantes químicos, já que aumenta a eficiência da biodisponibilidade de nutrientes e outras atividades relacionadas à melhoria de crescimento de plantas (SAXENA; CHANDRA; NAIM, 2013).

Entre esses microrganismos, os FMAs e as rizobactérias ganharam importância nas últimas duas décadas, conforme apresentado anteriormente. Os mecanismos moleculares que controlam as interações rizosféricas benéficas no solo são complexos e pouco conclusivos (DHAWI; DATTA; RAMAKRISHNA, 2015). Até o momento, sabe-se que os esporos produzidos pelos FMAs podem fornecer alimento e abrigo para as bactérias que colonizam as suas superfícies, protegendo-as de fatores de estresse ambiental, como dessecação, radiação, predação e salinidade (LEVY et al., 2009).

As rizobactérias estão entre os grupos microbianos que podem favorecer a germinação de esporos de FMAs devido à produção de alguns compostos como dióxido de carbono, etileno, amoníaco, aminas, alcoóis, compostos de enxofre entre outros (XAVIER; GERMIDA, 2003). Estes compostos influenciam expressamente a fisiologia das plantas por meio da elevação da permeabilidade das células das raízes, viabilizando a penetração do fungo e a formação da micorriza nas plantas (VIVAS et al., 2003). Por outro lado, as bactérias associadas aos esporos de FMAs podem 
provocar a intensificação e a rápida colonização pelo fungo (BHOWMIK; SINGH, 2004).

Além disso, no processo de penetração das hifas infectivas dos FMAs, pode ocorrer maior exsudação de nutrientes pela planta, o que intensificaria o crescimento de bactérias ali presentes (PAULA; REIS; DOBEREINER, 1991). Os compostos exsudados pelas hifas de FMAs, como a glicoproteína glomalina, também intervêm na constituição da comunidade microbiana na região influenciada pelas hifas (BOMBERG et al., 2003).

Diversos trabalhos no Brasil e no mundo mostram resultados positivos da coinoculação de FMAs e rizobactérias no crescimento e desenvolvimento de diferentes espécies vegetais, como milho (DHAWI; DATTA; RAMAKRISHNA, 2015; KUMAR et al., 2015; KRISHNAMOORTHY et al., 2016), no biocontrole de agentes de doenças em mamoeiro (HERNÁNDEZ-MONTIEL et al., 2013), na tolerância à seca de Lavandula dentata (ARMADA et al., 2016), na qualidade de frutos do tomateiro (BONA et al., 2016) ou mesmo na recuperação de áreas degradadas para aumentar a biodisponibilidade de nutrientes (RASHID et al., 2016).

Como visto, a literatura científica retrata claramente os efeitos benéficos da coinoculação de FMAs e rizobactérias em diversas culturas. Porém, em oliveira há poucos trabalhos no mundo relatando tais pesquisas, conforme retratado unicamente por Mridha et al. (2013), em uma rara revisão sobre o papel de FMAs e das rizobactérias no crescimento de plantas de oliveira. Assim, reforça-se a importância de estudos sobre os efeitos da coinoculação de FMAs e rizobactérias em oliveira, contribuindo para o melhor conhecimento da planta, desde o enraizamento até a produção de mudas, microrganismos esses que apresentam potencial de aplicação biotecnológica na olivicultura.

\section{CONSIDERAÇÕES FINAIS}

Apesar da existência de estudos em oliveira no que diz respeito à inoculação de FMAs e rizobactérias, em diversos locais do mundo, principalmente em países 
tradicionalmente produtores como Espanha, Itália, Árabia, entre outros, nas condições brasileiras tais estudos são ainda incipientes. Portanto, estudos devem ser incentivados, abordando aspectos microbiológicos e suas relações com as diferentes cultivares, condições edafoclimáticas, tanto em condições controladas de casa de vegetação, quanto em condições de campo, após transplantio de mudas coinoculadas, de forma a incentivar o desenvolvimento da olivicultura no Brasil.

\section{AGRADECIMENTOS}

Os autores agradecem à CAPES eà FAPEMIG pelo apoio financeiro concedido.

\section{REFERÊNCIAS}

ALBA, J. M. F.; FLORES, C. A.; WREGE, M. S. Zoneamento edafoclimático da olivicultura para o Rio Grande do Sul. Brasília: EMBRAPA, 2013. 92p.

ANDREOTE, F. D.; GUMIERE, T.; DURRER, A. Exploring interactions of plant microbiomes. Scientia Agricola, Piracicaba, v. 71, n. 6, p. 528-539, 2014.

ARMADA, E.; PROBANZA, A.; ROLDÁN, A.; AZCÓN, R. Native plant growth promoting bacteria Bacillus thuringiensis and mixed or individual mycorrhizal species improved drought tolerance and oxidative metabolism in Lavandula dentata plants. Journal of Plant Physiology, Toronto, v. 192, p. 1-12, 2016.

BALLUS, C. A.; MEINHART, A. D.; CAMPOS, F. A.; SILVA, L. F. D. O.; OLIVEIRA, A. F.; GODOY, H. T. A quantitative study on the phenolic compound, tocopherol and fatty acid contents of monovarietal virgin olive oils produced in the southeast region of Brazil. Food Research International, Ottawa, v. 62, n. 1, p. 74-83, 2014.

BATI, C. B.; SANTILLI, E.; LOMBARDO, L. Effect of arbuscular mycorrhizal fungi on growth and on micronutrient and macronutrient uptake and allocation in olive 
plantlets growing under high total Mn levels. Mycorrhiza, Berlin, v. 25, n. 2, p. 97 $108,2015$.

BHOWMIK, S. N.; SINGH, C. S. Mass multiplication of AM inoculum; effect of plant growth-promoting rhizobacteria and yeast in rapid culturing of Glomus mosseae. Current Science, Bangalore, v. 86, p. 705-709, 2004.

BOMBERG, M.;JURGENS, G.; SAANO, A.; SEN, R.; TIMONEN, S. Nested PCR detection of Archaea in defined compartments of pine mycorrhizospheres developed in boreal forest humus microcosms. FEMS Microbiology Ecology, Oxford, v. 43, n. 2, p. 163-171, 2003.

BOMPADRE, M. J.; PÉRGOLA, M.; FERNÁNDEZ BIDONDO, L.; COLOMBO, R. P.; SILVANI, V. A.; PARDO, A. G.; OCAMPO, J. A.; GODEAS, A. M. Evaluation of arbuscular mycorrhizal fungi capacity to alleviate abiotic stress of olive (Olea europaea L.) plants at different transplant conditions. The Scientific World Journal, London, v. 1, n. 1, p. 1-13, 2014.

BONA, E.; CANTAMESSA, S.; MASSA, N.; MANASSERO, P.; MARSANO, F.; COPETTA, A.; BERTA, G. Arbuscular mycorrhizal fungi and plant growth-promoting pseudomonads improve yield, quality and nutritional value of tomato: a field study. Mycorrhiza, Berlin, v. 27, n. 1, p. 1-11, 2016.

BORGES, T. H.; PEREIRA, J. A.; CABRERA-VIQUE, C.; LARA, L.; OLIVEIRA, A. F.; SEIQUER, I. Characterization of Arbequina virgin olive oils produced in different regions of Brazil and Spain: Physicochemical properties, oxidative stability and fatty acid profile. Food chemistry, Norwich, v. 215, p. 454-462, 2017.

CABALLERO, J. M.; DEL RÍO, C. Propagação da Oliveira por enraizamento de estacas semilenhosas sob nebulização. Informe Agropecuário, Belo Horizonte, v. 27, n. 231, p. 33-38, mar./abr. 2006.

CABALLERO-MELLADO, J. Microbiología agrícola e interacciones microbianas con plantas. Revista Latino Americana de Microbiología, Cidade do México, v. 48, n. 2, p. 154-161, 2006. 
CALVENTE, R.; CANO, C.; FERROL, N.; AZCÓN-AGUILAR, C.; BAREA, J. M. Analyzing natural diversity of arbuscular mycorrhizal fungi in olive tree (Olea europaea L.) plantations and assessment of the effectiveness of native fungal isolates as inoculants for commercial cultivars of olive plantlets. Applied Soil Ecology, Firenze, v. 26, n. 1, p. 11-19, 2004.

CALVO-POLANCO, M.; SÁNCHEZ-CASTRO, I.; CANTOS, M.; GARCÍA, J. L.; AZCÓN, R.; RUIZ-LOZANO, J. M.; AROCA, R. Effects of different arbuscular mycorrhizal fungal backgrounds and soils on olive plants growth and water relation properties under well-watered and drought conditions. Plant, Cell \& Environment, Logan, v. 39, n. 11, p. 2498-2514, 2016.

CARDOSO, E. J. B. N.; ANDREOTE, F. D. Microbiologia do solo. 2. ed. Piracicaba: ESALQ, 2016. 221p.

CARVALHO, D. D. C.; OLIVEIRA, D. F.; PASQUAL, M.; CAMPOS, V. P. Rizobactérias produtoras de promotores do crescimento de plantas. Pesquisa Agropecuária Tropical, Goiânia, v. 39, n. 4, p. 338-341, out./dez. 2009.

CASTILLO, P.; NICO, A. I.; AZCÓN-AGUILAR, C.; DEL RÍO RINCÓN, C.; CALVET, C.; JIMÉNEZ-DÍAZ, R. M. Protection of olive planting stocks against parasitism of rootknot nematodes by arbuscular mycorrhizal fungi. Plant Pathology, Hertfordshire, v. 55, n. 5, p. 705-713, 2006.

CHLIYEH, M.; OUAZZANI TOUHAMI, A.; FILALI-MALTOUF, A.; EL MODAFAR, C.; MOUKHLI, A.; OUKABLI, A.; DOUIRA, A. Effect of a composite endomycorrhizal inoculum on the growth of olive trees under nurseries conditions in Morocco. International Journal of Pure and Applied Bioscience, Kota, v. 2, n. 2, p. 1-14, 2014.

COUTINHO, E. F. A cultura da oliveira. Pelotas: Embrapa Clima Temperado, 2007. $143 \mathrm{p}$.

COUTINHO, E. F.; RIBEIRO, F. C.; CAPPELLARO, T. H. Cultivo de oliveira (Olea europaea L.). Pelotas: Embrapa Clima Temperado. Sistema de Produção, 2009. $125 \mathrm{p}$. 
COUTINHO, H. L. C.; JORGE, R. O.; HAERTER, J. A.; COSTA, V. B. Oliveira: Aspectos técnicos e cultivo no sul do Brasil. Brasília: EMBRAPA, 2015. 181p.

DHAWI, F.; DATTA, R.; RAMAKRISHNA, W. Mycorrhiza and PGPB modulate maize biomass, nutrient uptake and metabolic pathways in maize grown in miningimpacted soil. Plant Physiology and Biochemistry, Bari, v. 97, n. 1, p. 390-399, 2015.

EL TAWEEL, A. A.; OMAR, M. N. A.; SHAHEEN, S. A. Effect of inoculation by some plant growth promoting rhizobacteria (PGPR) on production of 'manzanillo' olive trees. In: INTERNATIONAL SYMPOSIUM ON ORGANIC MATTER MANAGEMENT AND COMPOST USE IN HORTICULTURE. 2014, ISHS. Anais... Leuven, ISHS, 2014, p. $245-254$.

ESTAÚN, V.; CAMPRUBÍ, A.; CALVET, C.; PINOCHET, J. Nursery and field response of olive trees inoculated with two arbuscular mycorrhizal fungi, Glomus intraradices and Glomus mosseae. Journal of the American Society for Horticultural Science, Alexandria, v. 128, n. 5, p. 767-775, 2003.

FERREIRA, G. M. R.; MELLONI, R.; SILVA, L. F. O.; MARTINS, F. B.; GONÇALVES, E. D. Fungos micorrízicos arbusculares no desenvolvimento de mudas de oliveira (Olea europaea L.) cultivadas no sul de Minas Gerais. Revista Brasileira de Ciência do Solo, Viçosa, v. 39, n. 2, p. 361-366, 2015.

FOLLI-PEREIRA, M. S.; MEIRA-HADDAD, L. S. A.; SOARES BAZZOLLI, D. M.; MEGUMI KASUYA, M. C. Micorriza arbuscular e a tolerância das plantas ao estresse. Revista Brasileira de Ciência do Solo, Viçosa, v. 36, n. 6, p. 1663-1679, 2012.

HERNÁNDEZ-MONTIEL, L. G.; RUEDA-PUENTE, E. O.; CORDOBA-MATSON, M. V.; HOLGUÍN-PEÑA, J. R.; ZULUETA-RODRÍGUEZ, R. Mutualistic interaction of rhizobacteria with arbuscular mycorrhizal fungi and its antagonistic effect on Fusarium oxysporum in Carica papaya seedlings. Crop Protection, Lincoln, v. 47, p. 61-66, 2013.

INTERNATIONAL OLIVE COUNCIL (IOC). Brasil: olive oil imports. Market 
Newsletter, 2016. Disponível em: < http://www.internationaloliveoil.org/estaticos/ view/135-imports-by-selected-markets > . Acesso em: 23 out. 2016.

KHABOU, W.; HAJJI, B.; ZOUARI, M.; RIGANE, H.; ABDALLAH, F. B. Arbuscular mycorrhizal fungi improve growth and mineral uptake of olive tree under gypsum substrate. Ecological Engineering, Prague, v. 73, n. 1, p. 290-296, 2014.

KRISHNAMOORTHY, R.; KIM, K.; SUBRAMANIAN, P.; SENTHILKUMAR, M.; ANANDHAM, R.; SA, T. Arbuscular mycorrhizal fungi and associated bacteria isolated from salt-affected soil enhances the tolerance of maize to salinity in coastal reclamation soil. Agriculture, Ecosystems \& Environment, Zurich, v. 231, n. 1, p. 233-239, 2016.

KUMAR, M.; KAUR, A.; PACHOURI, C. U.; SINGH, J. Growth promoting characteristics of rhizobacteria and AM Fungi for biomass amelioration of Zea mays. Archives of Biological Sciences, Belgrado, v. 67, n. 3, p. 877-887, 2015.

LEVY, A.; MERRITT, A. J.; MAYO, M. J.; CHANG, B. J.; ABBOTT, L. K.; INGLIS, T. J. Association between Burkbolderia species and arbuscular mycorrhizal fungus spores in soil. Soil Biology and Biochemistry, Amsterdam, v. 41, n. 8, p. 1757-1759, 2009.

LIVRAMENTO, D. E.; OLIVEIRA, A. F. Ecofisiologia da oliveira, alguns aspectos de fotossíntese, temperatura e radiação solar. Informe Agropecuário, Belo Horizonte, v. 27, n. 231, p. 27-32, mar./abr. 2006.

MALIK, N. S. A.; NUÑEZ, A.; MCKEEVER, L. C. Mycorrhizal Inoculation Increases Growth and Induces Changes in Specific Polyphenol Levels in Olive Saplings. Journal of Agricultural Science, Cambridge, v. 9, n. 2, p. 1-7, 2017.

MARIOSA, T. N. Potencial de enraizamento de Estacas Semilenhosas de Oliveira (Olea europaea L.) inoculadas com Rizobactérias. 2014. 69f. Dissertação (Mestrado em Ciências em Meio Ambiente e Recursos Hídricos) - Universidade Federal de Itajubá, Itajubá, 2014.

MECHRI, B.; TEKAYA, M.; CHEHEB, H.; ATTIA, F.; HAMMAMI, M. Accumulation of 
flavonoids and phenolic compounds in olive tree roots in response to mycorrhizal colonization: A possible mechanism for regulation of defense molecules. Journal of plant physiology, Toronto, v. 185, p. 40-43, 2015.

MEDDAD-HAMZA, A.; BEDDIAR, A.; GOLLOTTE, A.; LEMOINE, M. C.; KUSZALA, C.; GIANINAZZI, S. Arbuscular mycorrhizal fungi improve the growth of olive trees and their resistance to transplantation stress. African Journal of Biotechnology, Kenya, v. 9, n. 8, p. 1159-1167, Feb. 2010.

MEDDAD-HAMZA, A.; HAMZA, N.; NEFFAR, S.; BEDDIAR, A.; GIANINAZZI, S.; CHENCHOUNI, H. Spatiotemporal variation of arbuscular mycorrhizal fungal colonization in olive (Olea europaea L.) roots across a broad mesic-xeric climatic gradient in North Africa. Science of The Total Environment, Barcelona, v. 583, p. 176-189, 2017.

MEKAHLIA, M. N.; BEDDIAR, A.; CHENCHOUNI, H. Mycorrhizal dependency in the olive tree (Olea europaea) across a xeric climatic gradient. Advances in Environmental Biology, Amman, v. 7, n. 9, p. 2166-2174, 2013.

MELLO, L. D.; PINHEIRO, M. F. Aspectos físico-químicos de azeites de oliva e de folhas de oliveira provenientes de cultivares do RS, Brasil. Alimentos e Nutrição, Araraquara, v. 23, n. 4, p. 537-548, out./dez. 2012.

MESQUITA, D. L.; OLIVEIRA, A. F.; MESQUITA, H. A. Aspectos econômicos da produção e comercialização do azeite de oliva e azeitona. Informe Agropecuário, Belo Horizonte, v. 27, n. 231, p. 7-12, mar./abr. 2006.

MONTERO-CALASANZ, M. C.; SANTAMARÍA, C.; ALBAREDA, M.; DAZA, A.; DUAN, J.; GLICK, B. R.; CAMACHO, M. Alternative rooting induction of semi-hardwood olive cuttings by several auxin-producing bacteria for organic agriculture systems. Spanish Journal of Agricultural Research, Madrid, v. 11, n. 1, p. 146-154, 2013.

MONTES-BORREGO, M.; METSIS, M.; LANDA, B. B. Arbuscular Mycorrhizal Fungi Associated with the Olive Crop across the Andalusian Landscape: Factors Community Differentiation. Plos One, San Francisco, v. 9, n. 5, p. 1-12, May. 2014. 
MOREIRA, F. M. S.; SIQUEIRA, J. O. Microbiologia e Bioquímica do Solo. 2. ed. Lavras: Editora UFLA, 2006. 729p.

MRIDHA, M. A. U.; AL-QARAWI, A. A.; AL-OUD, S. S.; AL-BARAKAH, F. N. Status and Need of Research on Growth Improvement of Olive (Olea europaea L.) with Microbial Inoculants in Saudi Arabia. Journal of Pure and Applied Microbiology, Shahjahanabad, v. 7, n. 3, p. 1861-1868, 2013.

NAVARRO, C.; PARRA, M. A. Plantacion. In: BARRANCO, D.; FERNANDEZ-ESCOBAR, R. F. El cultivo del olivo. 6. ed. Madri: Mundi-Prensa, 2008. p. 93-125.

NEVES, T. S.; CARPANEZZI, A. A.; ZUFFELLATO-RIBAS, K. C.; MARENCO, R. A. Enraizamento de corticeira-da-serra em função do tipo de estaca e variações sazonais. Pesquisa Agropecuária Brasileira. Brasília, v. 41, n. 12, p. 1699-1705, dez. 2006.

OLIVEIRA, A. F. D.; CHALFUN, N. N. J.; ALVARENGA, Â. A.; VIEIRA NETO, J.; PIO, R.; OLIVEIRA, D. L. D. Estaquia de oliveira em diferentes épocas, substratos e doses de AIB diluído em NaOH e álcool. Ciência e Agrotecnologia, Lavras, v. 33, n. 1, p. 79 85, jan./fev. 2009.

OLIVEIRA, A. F. Propagação da oliveira por enraizamento de estacas semilenhosas. Edição 90. Belo Horizonte: EPAMIG, 2008. 48p.

OLIVEIRA, A. F.; ANTUNES, L. E. C.; SCHUCH, M. W. Caracterização morfológica de cultivares de oliveira em coleção e considerações sobre o seu cultivo no Brasil. Informe Agropecuário, Belo Horizonte, v. 27, n. 231, p. 55-62, 2006.

OLIVEIRA, A. F.; VIEIRA NETO, J.; GONÇALVES, E. D.; MESQUITA, H. A. Pioneirismo marca pesquisa sobre oliveira em Minas Gerais. Informe Agropecuário, Belo Horizonte, v. 30, p. 108-117, 2009.

OLIVEIRA, M. C.; RAMOS, J. D.; PIO, R.; CARDOSO, M. G. Características fenológicas e físicas e perfil de ácidos graxos em oliveiras no sul de Minas Gerais. Pesquisa Agropecuária Brasileira, Brasília, v. 47, n. 1, p. 30-35, jan. 2012. 
PAULA, M. A.; REIS, V. M.; DÖBEREINER, J. Interactions of Glomus clarum with A. dizotrophicus in infection of sweet potato, sugar cane, sweet sorghum. Biology and Fertility of Soils, Berlin, v. 11, p. 111-115, 1991.

PEYVANDI, M.; FARAHANI, F.; MAZINANI, M. H.; NOORMOHAMADI, Z.; ATAII, S.; ASGHARZADE, A. Pseudomonas fluorescent and its ability to promote root formation of olive microshoots. International Journal of Plant Production, Gorgan, v. 4, n. 1, p. 63-66, Jan. 2010.

PORRAS-SORIANO, A.; SORIANO-MARTÍN, M. L.; PORRAS-PIEDRA, A.; AZCÓN, R. Arbuscular mycorrhizal fungi increased growth, nutrient uptake and tolerance to salinity in olive trees under nursery conditions. Journal of Plant Physiology, Toronto, v. 166, n. 13, p. 1350-1359, 2009.

RASHID, M. I.; MUJAWAR, L. H.; SHAHZAD, T.; ALMEELBI, T.; ISMAIL, I. M.; OVES, M. Bacteria and fungi can contribute to nutrients bioavailability and aggregate formation in degraded soils. Microbiological research, Brussels, v. 183, p. 26-41, 2016.

SAXENA, J.; CHANDRA, S.; NAIN, L. Synergistic effect of phosphate solubilizing rhizobacteria and arbuscular mycorrhiza on growth and yield of wheat plants. Journal of soil science and plant nutrition, Temuco, v. 13, n. 2, p. 511-525, 2013.

SCHILIRÒ, E.; FERRARA, M.; NIGRO, F.; MERCADO-BLANCO, J. Genetic responses induced in olive roots upon colonization by the biocontrol endophytic bacterium Pseudomonas fluorescens PICF7. Plos One, San Francisco, v. 7, n. 11, p. 1-11, 2012.

SEIFI, E.; TEYMOOR, Y. S.; ALIZADEH, M.; FEREYDOONI, H. Olive mycorrhization: Influences of genotype, mycorrhiza, and growing periods. Scientia Horticulturae, Columbia, v. 180, n. 1, p. 214-219, 2014.

SIDHOUM, W.; FORTAS, Z. Effect of arbuscular mycorrhizal fungi on growth of semi-woody olive cuttings of the variety "Sigoise" in Algeria. American Journal of Research Communication, San Antonio, v. 1, p. 244-57, 2013.

SILVA, G. L. G.; MELLO, A. S. O desenvolvimento de tecnologias sociais em um 
centro de pesquisas científicas no sul de Minas. Janus, Lorena, v. 11, n. 20, p. 8094, jul./dez. 2014.

SILVA, F. J.; RIBEIRO, R. C. F.; XAVIER, A. A.; NETO, J. A. S.; SOUZA, M. A.; DIASARIEIRA, C. R. Rizobactérias associadas a materiais orgânicos no controle de Meloidogyne javanica em tomateiro. Horticultura Brasileira, Vitória da Conquista, v. 34, n. 1, p. 59-65, jan./mar. 2016.

SILVA, L. F. O.; OLIVEIRA, A. F.; PIO, R.; RUIZ ZAMBON, C.; OLIVEIRA, D. L. Enraizamento de estacas semilenhosas de cultivares de oliveira. Bragantia, Campinas, v. 71, n. 4, p. 488-492, 2012.

SILVA, T. F.; MELLONI, R.; MELLONI, E. G. P.; GONÇALVES, E. D. Bactérias diazotróficas não simbióticas e enraizamento de estacas semilenhosas de oliveira (Olea europaea L.). Ciência Florestal, Santa Maria, v. 27, n. 1, p. 61-71, jan./mar., 2017.

TAPIA, F.; ASTORGA, H.; IBACACHE, A.; MARTINEZ, L.; SIERRA, C.; QUIROZ, C.; LARRAIN, P.; RIVEROS, F. Manual del cultivo del olivo. La Serena (Chile): INIA, 2003. 128 p. (INIA. Boletin 101).

TEKAYA, M.; MECHRI, B.; MBARKI, N.; CHEHEB, H.; HAMMAMI, M.; ATTIA, F. Arbuscular mycorrhizal fungus Rhizophagus irregularis influences key physiological parameters of olive trees (Olea europaea L.) and mineral nutrient profile. Photosynthetica, Praha, p. 1-10. 2016.

TOFOLI, J. G.; DOMINGUES, R. J.; FERRARI, J. T.; NOGUEIRA, E. M. C. Doenças fúngicas da oliva: sintomas, etiologia e manejo. Biológico, São Paulo, v. 75, n. 1, p. 53-61, 2013.

VAFADAR, F.; AMOOAGHAIE, R.; OTROSHY, M. Effects of plant-growth-promoting rhizobacteria and arbuscular mycorrhizal fungus on plant growth, stevioside, NPK, and chlorophyll content of Stevia rebaudiana. Journal of Plant Interactions, London, v. 9, n. 1, p. 128-136, 2013.

VALMORBIDA, J.; BOARO, C. S. F.; LESSA, A. O.; SALERNO, A. R. Enraizamento de 
estacas de Trichilia catigua A. Juss (catigua) em diferentes estações do ano. Revista Árvore, Viçosa, v. 32, n. 3, p. 435-442, 2008.

VEJAN, P.; ABDULLAH, R.; KHADIRAN, T.; ISMAIL, S.; NASRULHAQ BOYCE, A. Role of plant growth promoting rhizobacteria in agricultural sustainability - a review. Molecules, Basel, v. 21, n. 5, p. 573, 2016.

VIEIRA NETO, J.; OLIVEIRA, A. F.; OLIVEIRA, N. C.; DUARTE, H. S. S.; GONÇALVES, E. D. Aspectos técnicos da cultura da oliveira. Belo Horizonte: Empresa de Pesquisa Agropecuária de Minas Gerais, 2008. 56p.

VIEIRA, V. C. S.; MELLONI, R.; VIEIRA NETO, J. Avaliação da interação micorrízica em cultivares de oliveira (Olea europaea L.). Revista Brasileira de Ciência do Solo, Viçosa, v. 35, n. 6, p. 1885-1892, 2011.

VIVAS, A.; AZCÓN, R.; BIRÓ, B.; BAREA, J. M.; RUIZ-LOZANO, J. M. Influence of bacterial strains isolated from lead-polluted soil and their interactions with arbuscular mycorrhizae on the growth of Trifolium pratense L. under lead toxicity. Canadian Journal of Microbiology, Ottawa, v. 49, n. 10, p. 577-588, 2003.

XAVIER, L. J. C.; GERMIDA, J. J. Bacteria associated with Glomus clarum spores influence mycorrhizal activity. Soil Biology and Biochemistry, Amsterdam, v. 35, n. 3, p. 471-478, 2003.

WREGE, M. S.; COUTINHO, E. F.; PANTANO, A. P.; JORGE, R. O. Distribuição potencial de oliveiras no Brasil e no mundo. Revista Brasileira de Fruticultura, Jaboticabal, v. 37, n. 3, p. 656-666, 2015.

WREGE, M.; COUTINHO, E.; STEINMETZ, S.; REISSER JUNIOR, C.; ALMEIDA, I. R.; MATZENAUER, R.; RADIN, B. Zoneamento agroclimático para oliveira no estado do Rio Grande do Sul. Pelotas: Embrapa Clima Temperado, 2009. 24p. 